\title{
Shear-mode Crack Initiation Behavior in the Martensitic and Bainitic Microstructures
}

\author{
Kentaro Wada ${ }^{1,2,}$, Soma Yoshimura $^{1}$, Tomoko Yamamoto $^{3}$, Yoshihiro Ohkomori ${ }^{3}$ and Hisao Matsunaga ${ }^{4,5,6}$ \\ ${ }^{1}$ Guraduate School of Engineering, Kyushu University, 744 Motooka, Nishi-ku, Fukuoka 819-0395, Japan \\ ${ }^{2}$ AIST-Kyushu University Hydrogen Materials Laboratory (HydroMate), 744 Motooka, Nishi-ku, Fukuoka 819-0395, Japan \\ ${ }^{3}$ Japan Casting \& Forging Co., 46-59 Sakinohama Nakabaru Tobata-ku, Kitakyushu 804-8555, Japan \\ ${ }^{4}$ Department of Mechanical Engineering, Kyushu University, 744 Motooka, Nishi-ku, Fukuoka 819-0395, Japan \\ ${ }^{5}$ Research Center for Hydrogen Industrial Use and Storage (HYDROGENIUS), Kyushu University, 744 Motooka, Nishi-ku, Fukuoka \\ 819-0395, Japan \\ ${ }^{6}$ International Institute for Carbon-Neutral Energy Research (I2CNER), Kyushu University,744 Motooka, Nishi-ku, Fukuoka 819- \\ 0395, Japan
}

\begin{abstract}
Fully reversed torsional fatigue tests were conducted to elucidate the behaviour of shear-mode crack initiation and propagation in one martensitic and two bainitic steels. The relationship between the crack initiation site and microstructure was investigated by means of an electron backscatter diffraction (EBSD) technique. From the $S-N$ diagram, two notable results were obtained: (i) the shear-mode crack was initiated on the prior austenitic grain boundary in martensitic steel, while in bainitic steels, the crack was initiated along the $\{110\}$ plane; one of the slip planes of bcc metals, and (ii) the torsional fatigue limit of lower bainitic steel with finer grains was $60 \mathrm{MPa}$ higher than that of upper bainitic steel with coarser grains even though the hardnesses were nearly equivalent. The mechanism determining the torsional fatigue strength in these steels is discussed from the viewpoint of microstructure morphology.
\end{abstract}

\section{Introduction}

Rolling contact fatigue (RCF) is one of the critical failure modes in the components with Hertzian contact surfaces such as ball bearings, back-up rolls and rail and wheel systems in trains. With the aim of improving the RCF strength, considerable efforts have been made especially in improving the cleanness of material $[1,2]$. However, the improvement of cleanness does not result in the improvement of the strength in case that nonmetallic inclusions no longer affect the crack initiation in RCF process $[3,4]$. In other words, there is a threshold inclusion size at which the fracture origin changes from inclusions to microstructural features. Namely, to improve the RCF strength effectively, two factors should be considered: the threshold size of detrimental inclusion for each microstructure, and an alternative fracture origin when cleanness is below the threshold.

Several studies have focused on the transition point of the fracture origin from the defect to the matrix. For example, Murakami et al. [3] documented that the fatigue limit increases with a decrease in the size of defect (e.g. hole and inclusion). The defect smaller than a certain size is no longer detrimental to the strength, below which the reduction of defect size does not lead to the improvement of strength. Most of the existing studies have targeted the opening-mode (mode I) crack. By contrast, number of studies on shear-mode (modes II and
III) crack is limited, though shear-mode crack growth plays a significant role in the RCF process [5-8]. Allegedly, such a transition of the crack initiation site also occurs in the shear-mode cracking; however, the phenomenon is still unclear. Therefore, the first purpose of this study is to elucidate the transition behaviour of the initiation site in the case of shear-mode cracking.

Elucidating potential initiation sites in the matrix except the inclusions - are also important when the cleanness exceeds a certain point. For martensitic and bainitic steels, several researchers have pointed out in the case of uni-axial loading that crack initiation site is dependent on the material type and microstructure. For example, prior austenitic grain boundary in martensitic steels $[9,10],\{110\}$ slip planes or bainitic lath/block interface in bainitic steels [11] and martensite-austenite constituent [12] have been reported as crack initiation sites. However, it has not yet been clarified which microstructural feature dominates the shear-mode crack initiation in each case. To improve the RCF strength of materials, a better understanding of the role of microstructure on the shear-mode initiation is necessary; and is therefore the second purpose of this study.

In this study, in order to reveal the initiation behavior of shear-mode crack, torsional fatigue tests were conducted using a martensitic steel and the two types of bainitic steel with or without drill holes. In addition, 
shear-mode crack initiation sites, except for the inclusion or defect, are discussed employing the EBSD technique.

\section{Experimental}

Three types of material were prepared. The first material is JIS-SKD61, called "back-up roll steel" (BR), whose

Table 2 Mechanical properties of martensitic steel JIS-SKD61 (BR), upper bainitic steels (MS-U) and lower bainitic steel (MS-L).

\begin{tabular}{|c|c|c|c|}
\hline & BR & MS-U & MS-L \\
\hline Vickers hardness, $H V$ & 560 & 329 & 334 \\
\hline $0.2 \%$ proof stress, $\sigma_{0.2}$ & $1384 \mathrm{MPa}$ & $895 \mathrm{MPa}$ & $943 \mathrm{MPa}$ \\
\hline Tensile strength, $\sigma_{\mathrm{B}}$ & $1823 \mathrm{MPa}$ & $1064 \mathrm{MPa}$ & $1059 \mathrm{MPa}$ \\
\hline Reduction in area, $\varphi$ & $33.6 \%$ & $56.0 \%$ & $66.0 \%$ \\
\hline
\end{tabular}

chemical composition is $0.45 \mathrm{C}-5 \mathrm{Cr}-0.8 \mathrm{Mo}-0.3 \mathrm{~V}$. The second material is called "alloy steel for marine shaft" (MS), whose chemical composition is $0.4 \mathrm{C}-1 \mathrm{Cr}-0.5 \mathrm{Mo}$. The BR was heat-treated at $1030{ }^{\circ} \mathrm{C}$ for 0.5 hours, then subsequently oil-quenched and tempered at $515{ }^{\circ} \mathrm{C}$ to obtain a martensitic microstructure. The MS was heattreated to obtain two types of microstructure: upper bainite (MS-U) and lower bainite (MS-L). The microstructure and mechanical properties of each steel are shown in Fig. 1 and Table 1, respectively. In Figs. 1 (a), (c) and (e), crystal orientations are shown. In Figs. 1 (b), (d) and (f), red lines represent the high-angle grain boundaries on which the crystal misorientation is $15^{\circ}$ or greater. The density of the high-angle grain boundary is higher in MS-L than in MS-U, meaning that MS-L has smaller grains. It is noted that MS-L occasionally includes coarse-grains as indicated by yellow arrows in Fig. 1 (f).

Cylindrical specimens were machined from
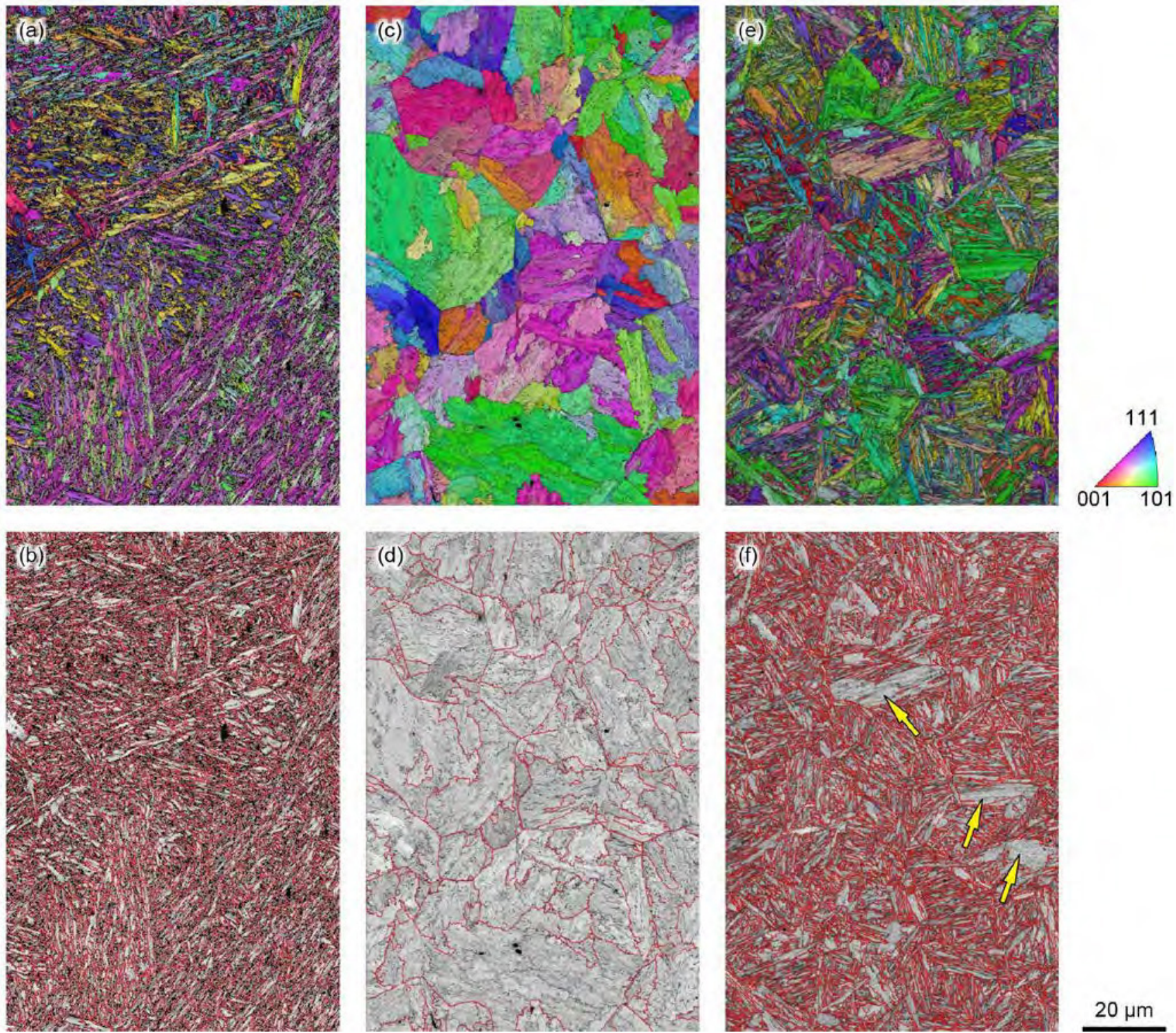

$20 \mu \mathrm{m}$

Fig. 1 Crystal orientation (a, c and e) and high-angle grain boundary traces (b, d and f) of martensitic steel SKD61 (a and b), upper bainitic steel (c and d) and lower bainitic steel (e and f). Yellow arrows indicate coarse grains. 
these materials. The dimensions of the parallel part are $6.5 \mathrm{~mm}$ in diameter and $13 \mathrm{~mm}$ in length in BR specimens, and $5 \mathrm{~mm}$ in diameter and $21 \mathrm{~mm}$ in length in the MS specimens. The specimen surface was buffed with a diamond paste after emery polishing. In some BR specimens, a drill hole of $100 \mu \mathrm{m}$ or $200 \mu \mathrm{m}$ in diameter and depth was introduced onto the centre of parallel part.

Torsional fatigue tests were conducted at stress ratio, $R$, of -1 and test frequencies of $45 \sim 50 \mathrm{~Hz}$. In the test of BR specimens, a static axial compression of $1000 \mathrm{MPa}$ was superimposed on cyclic torsion to facilitate the crack growth in shear-mode direction by supressing the opening-mode crack branching. Fatigue tests were periodically halted to observe crack growth behavior by means of the plastic replica method.

The crystal orientation and misorientation angles of grain boundaries in each microstructure were analysed before and after the fatigue tests by using EBSD. Surface of all the samples was finished with buff polishing using colloidal silica. Step size for the EBSD analysis was $0.5 \mu \mathrm{m}$ and the acceleration voltage was 15 $\mathrm{kV}$.

\section{Results and discussion}

\subsection{Results for back-up roll steel}

In Fig. 2, $S-N$ data of $\mathrm{BR}$ are presented. Black circles denote the results of smooth specimens, and red rectangle and green diamond denote those of holed specimens. It seems that both the holes of $100 \mu \mathrm{m}$ and $200 \mu \mathrm{m}$ led to no significant degradation of the fatigue life of BR. In the case of $100 \mu \mathrm{m}$ hole, no crack initiated from the hole, whereas in the case of $200 \mu \mathrm{m}$, openingmode cracks propagated from the hole in the directions oblique to the specimen axis, demonstrating that a defect smaller than $100 \mu \mathrm{m}$ in size does not degrade the fatigue strength of BR.

Fig. 3 (a) shows a crack after the fatigue test at stress amplitude $\tau_{\mathrm{a}}$ of $540 \mathrm{MPa}$. Considering the directions of crack branching, any point in the region surrounded by red broken line was assumed to be the crack initiation site. Fig. 3 (b) presents the crystal orientation around the crack initiation site. The microstructure around the crack can clearly be divided into two regions: the upper region, coupled with the colours blue, red and orange, and the lower region, coupled with the colours green, yellow and orange. The difference in colours represents the different prior austenite grains, meaning that the crack initiation site was the prior austenite grain boundary.

\subsection{Results for alloy steel for marine shaft}


Brue triangles and red reversed triangles in Fig. 2 show the $S-N$ data of MS-U and MS-L, respectively. Two notable results were obtained. Firstly, the fatigue strength of MS-L had a large scatter. Secondly, the fatigue strength of MS-L was more than $60 \mathrm{MPa}$ as high as that of MS-U. Fig. 4 shows the fracture surfaces of MS-L and MS-U, where no defect (e.g. inclusion) was found at crack initiation sites. The result inferred that the cracks were initiated in the matrix.

Fig. 5 (a) presents the crack growth behaviour in an MS-U specimen tested at $\tau_{\mathrm{a}}=280 \mathrm{MPa}$. Firstly, a fatigue crack was initiated and grew in shear-mode in the

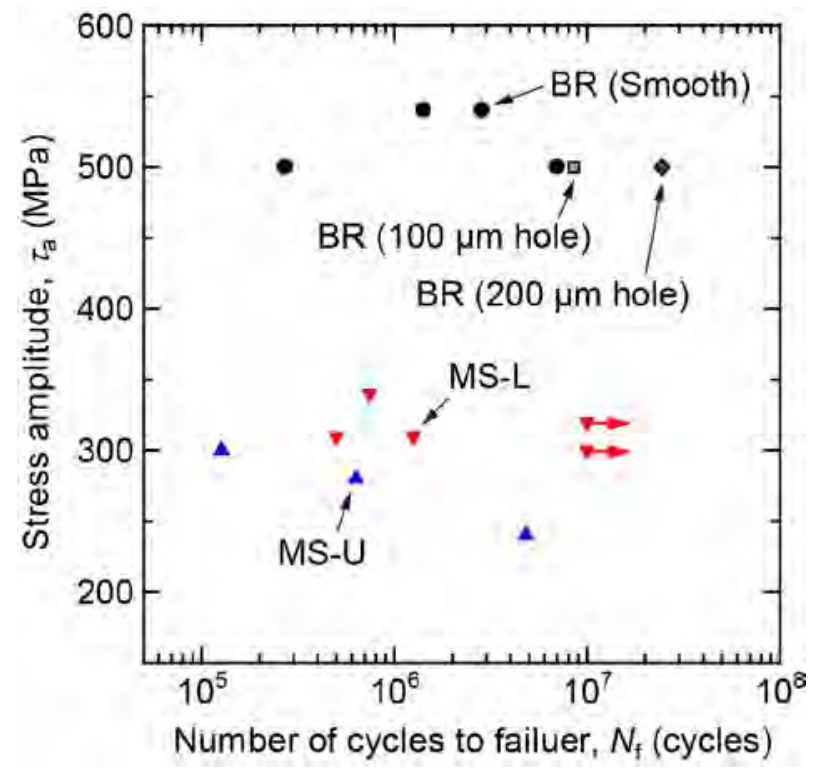

Fig. $2 S-N$ diagram of martensitic steel JIS-SKD61 (BR), upper bainitic steels (MS-U) and lower bainitic steel (MS-L). matrix, and subsequently branched into opening-mode. To investigate the initiation site of the shear-mode crack, crystal feature was investigated employing EBSD. Fig. 5 (b) shows the crystal orientation around the crack initiation site in MS-U, indicating that the shear-mode crack was initiated and propagated transgranulary. In Fig. 5 (c), red lines represent the high-angle grain boundaries (misorientation of $15^{\circ}$ or greater), whereas blue lines represent the $\{110\}$ planes. The result clearly exhibits that the shear-mode crack was initiated along $\{110\}$ plane, which is one of the slip planes in bcc metals.
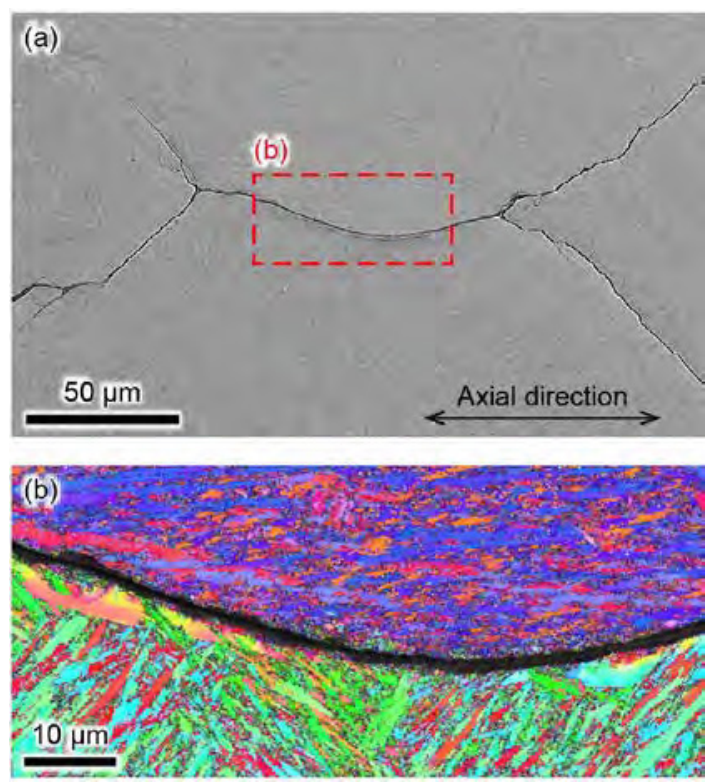

Fig. 3 Mopholorgy of shear-mode fatigue crack (a), and cristal orientaion mapping around the crack initiation site (b) on the JIS-SKD61 (BR) martensitic steel. The region surrounded by red broken line was assumed to be the crack initiation site.
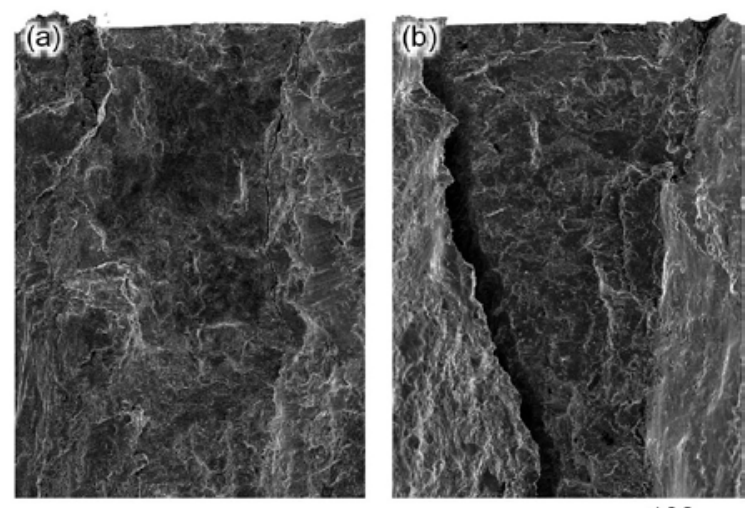

$100 \mu \mathrm{m}$

Fig. 4 Initiation site of shear-mode crack on fracture surface. MS-U tested at $\tau_{\mathrm{a}}=240 \mathrm{MPa}(\mathrm{a})$, and MS-L tested at $\tau_{\mathrm{a}}=310 \mathrm{MPa}$. 
In MS-L, non-propagating cracks were observed in unbroken specimens as demonstrated in Fig. 6 (a). Fig. 6 (b) presents the crystal orientation around the nonpropagating crack, exhibiting that the shear-mode crack was transgranulary initiated also in MS-L. In Fig. 6 (c), the high-angle grain boundaries and $\{110\}$ planes were presented, exhibiting that the shear-mode crack was initiated along the $\{110\}$ plane, as was the case with MS-U. The microstructure around the crack was coarser than surroundings, and the crack was arrested in the region with finer grains.

\subsection{Effect of microstructural morphology on}
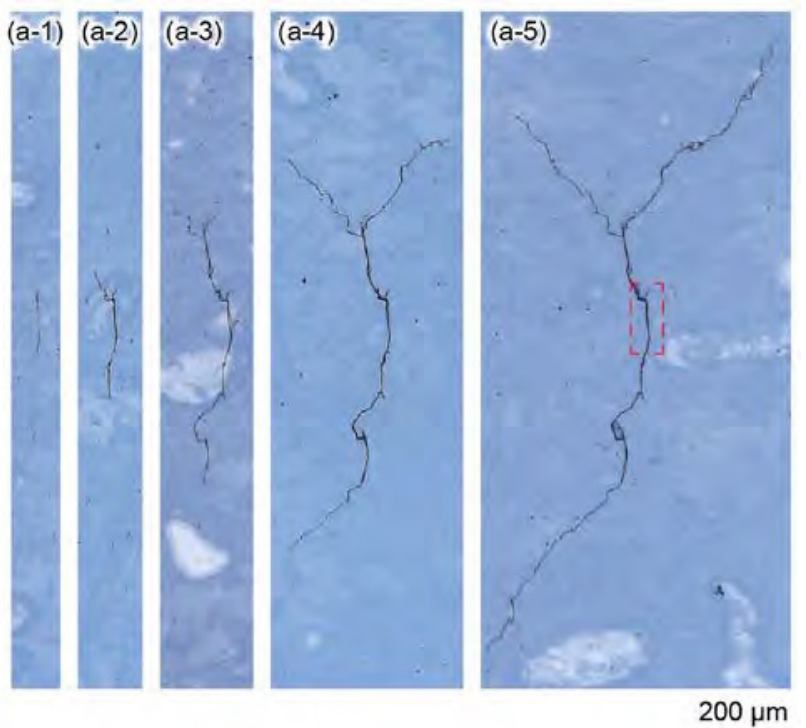

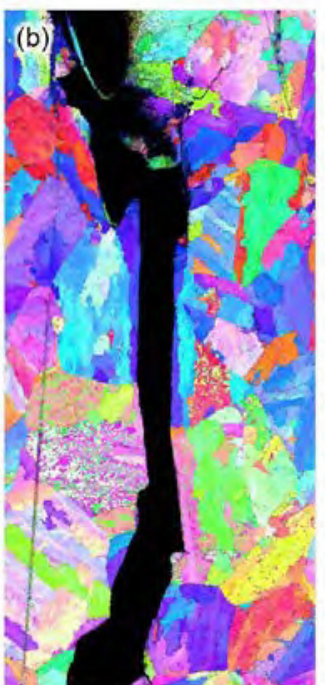

Axial direction
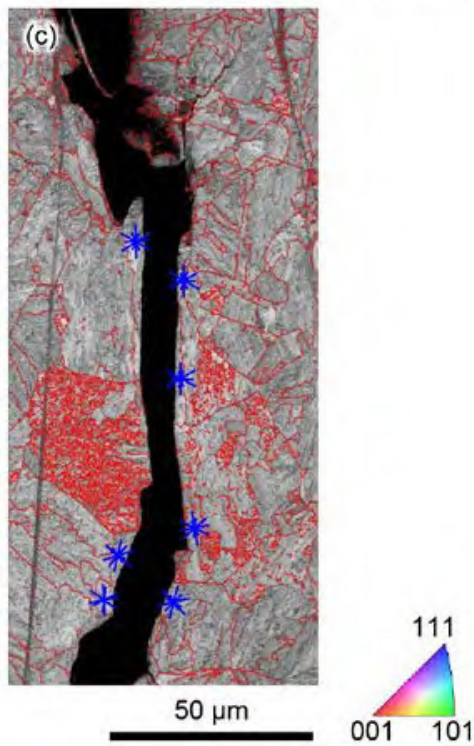

Fig. 5 Crack growth behavior on the MS-U upper bainitic steel tested at $\tau_{\mathrm{a}}=280 \mathrm{MPa}$ (a-1 5), crack orientation mapping (b) and high-angle grain boundary traces (c) around the crack initiation site indicated by red broken line in (a-5). The applied cycles are $1.7 \times 10^{5}$ cycles in $(\mathrm{a}-1), 2.7 \times 10^{5}$ cycles in $(\mathrm{a}-2)$, $3.7 \times 10^{5}$ cycles in (a-3), $4.7 \times 10^{5}$ cycles in (a-4) and $5.2 \times 10^{5}$ cycles in (a-5).

\section{shear-mode crack initiation}

As demonstrated above, the crack initiation site varied from intergranular to transgranular, i.e. a grain boundary in the martensitic steel and $\{110\}$ slip planes in the bainitic steels. In the following, the reason for the difference is discussed.

Overall, the intergranular fracture occurs only in a limited number of cases. For example, it has been reported that intergranular fracture occurs by hydrogen
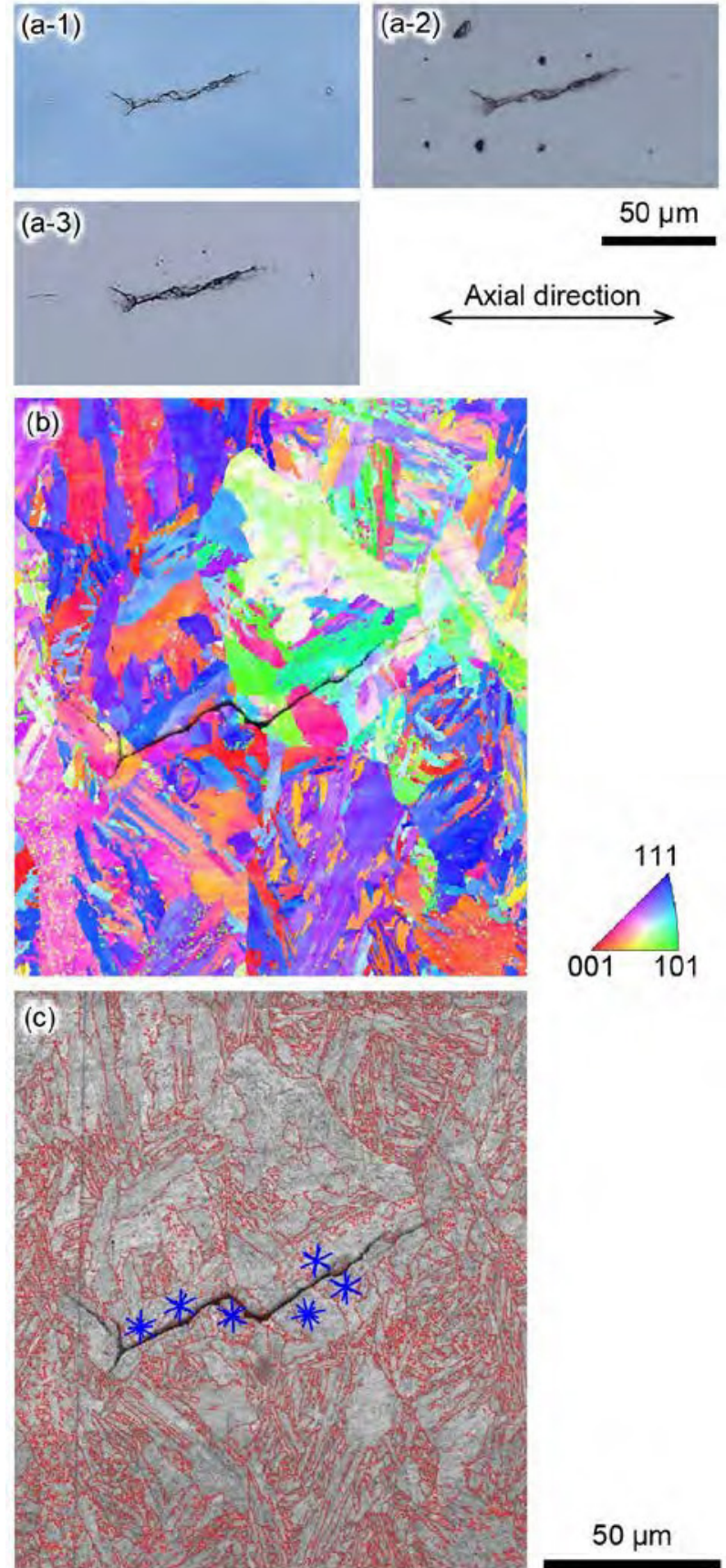

$50 \mu \mathrm{m}$

Fig. 6 Non-propagating crack observed in an MS-L specimen, tested at $320 \mathrm{MPa}(\mathrm{a}-1 \sim 3)$, crystal orientation mapping (b) and high-angle grain boundary traces (c) around the nonpropagating crack. The applied cycles are $5.0 \times 10^{5}$ cycles in (a$1), 2.0 \times 10^{6}$ cycles in (a-2) and $1.0 \times 10^{7}$ cycles in (a-3). 
embrittlement [13], tempering embrittlement [10, 14], intergranular segregation [15-17] and so on [18]. In addition, also in the case of cyclic shear loading under crack opening stress, intergranular cracking occurred $[19,20]$.

In BR having martensitic microstructure, it is assumed that an intergranular segregation occurred in the tempering process, weakening the grain boundary, in which the responsible elements in BR are $\mathrm{P}$ and $\mathrm{S}$ [16]. The existence of such an intergranular segregation should be investigated in the future to make ensure its role on the fracture process.

\subsection{Mechanism determining torsional fatigue strength}

It is well known that the fatigue limit of matrix obtained via uniaxial fatigue tests is well correlated with Vickers hardness [21]:

$$
\sigma_{\mathrm{w}}=1.6 \mathrm{HV}
$$

This correlation predicts that the fatigue limits of two types of MS steel with equivalent hardness $(H V \approx 330)$ are the same under uniaxial loading. However, in fact, the torsional fatigue limit, $\tau_{\mathrm{w}}$, of MS-L was more than 60 $\mathrm{MPa}$, as high as that of MS-U. The followings are cited as possible causes.

It has been reported that high-angle grain boundary plays a significant role as an obstacle for the crack growth along slip planes $[11,12]$. As was shown in Fig. 1 , MS-L had a higher density of the high-angle grain boundary than MS-U. This can contribute to the higher resistance against the shear-mode initiation and growth of microstructurally small crack.

In addition, the sizes of crack initiation units are different between MS-U and MS-L. As demonstrated above, shear-mode cracks were initiated along slip planes, meaning that one grain can act as the crack initiation unit. In MS-L, non-propagating cracks were observed at the fatigue limit. Namely, the fatigue limit of MS-L was determined by a crack growth threshold. In such a case, the grains, which are preferentially oriented to crack initiation, can act like an initial defect in the fatigue process. In MS-L, coarse-grained regions were occasionally observed (cf. yellow arrows in Fig. 1(f)), which were confirmed to become crack initiation sites as shown in Fig. 6. The result infers that such a large grain can preferentially initiate the shear-mode crack in MS-L. It is assumed that the scatter of the maximum size of the coarse-grain resulted in the scatter of the fatigue strength of MS-L (cf. Fig. 2), and the difference in the maximum grain size between MS-U and MS-L resulted in the difference in the fatigue limits, based on the weakest link hypothesis.

\section{Conclusions}

To elucidate the role of microstructure on shear-mode fatigue crack behaviour, torsional fatigue tests were conducted with three types of steels with a martensite, an upper bainite and a lower bainite. The following conclusions were obtained:
(1) In the martensitic steel JIS-SKD61, the hole of 100 $\mu \mathrm{m}$ in diameter and depth did not affect the fatigue process. Thus, it is assumed that the defect smaller than $100 \mu \mathrm{m}$ in size has no effect on the fatigue strength.

(2) In the martensitic steel, shear-mode crack was initiated along the prior austenitic grain boundary, meaning that attention should be paid not only on increasing cleanness, but also on controlling the microstructure for improving the resistance of material against shear-mode cracking.

(3) In both the two types of bainitic steel, shear-mode cracks were initiated along $\{110\}$ slip plane. Even in the lower bainitic steel with finer microstructure, the cracks were preferentially initiated from a coarse-grained region. The results revealed that controlling grain size is important to increase the torsional fatigue strength.

\section{References}

1 Y. Ohkomori, I. Kitagawa, K. Shinozuka, T. Toriyama, K. Matsuda, Y. Murakami, Tetsu-toHagane, 77, 438 (1991)

2 Y. Ohkomori, C. Sakae, Y. Murakami, J. Soc. Mater. Sci., Jpn., 50, 249 (2001)

3 Y. Murakami, M. Endo, Int. J. Fatigue, 16, 163 (1994)

4 Y. Murakami, T. Endo, Int. J. Fatigue, 2, 23 (1980)

5 A.V. Olver, Proc. Inst. Mech. Eng. P. J. Sport. Eng. Technol., 219, 313 (2005)

6 P.E. Bold, M.W. Brown, R.J. Allen, Wear, 144, 307 (1991)

7 H. Matsunaga, N. Shomura, S. Muramoto, M. Endo, Fatigue Fract. Eng. Mater. Struct., 34, 72 (2011)

8 S. Beretta, M. Boniardi, M. Carboni, H. Desimone, Eng. Fail. Anal., 12, 157 (2005)

9 M.-L. Zhu, F.-Z. Xuan, G.-Z. Wang, Mater. Sci. Eng. A, 515, 85 (2009)

10 K.S. Ravichandran, E.S. Dwarakadasa, Metallurgical Transactions A, 21, 3171 (1990)

11 M.C. Marinelli, I. Alvarez-Armas, U. Krupp, Mater. Sci. Eng. A, 684, 254 (2017)

12 L. Lan, C. Qiu, D. Zhao, X. Gao, L. Du, Mater. Sci. Eng. A, 529, 192 (2011)

13 C.J. McMahon, Eng. Fract. Mech., 68, 773 (2001)

14 J.H. Hollomon, TRANSACTIONS OF THE AMERICAN SOCIETY FOR METALS, 36, 473 (1946)

15 C.T. Liu, C.L. White, J.A. Horton, Acta Metall., 33, 213 (1985)

16 J.R. Rice, J.-S. Wang, Mater. Sci. Eng. A, 107, 23 (1989)

17 H. Erhart, H.J. Grabke, Met. Sci., 15, 401 (1981)

18 C.L. Briant, S.K. Banerji, International Metals Reviews, 23, 164 (1978)

19 S. Okazaki, K. Wada, H. Matsunaga, M. Endo, Eng. Fract. Mech., 174, 127 (2017)

20. A. Otsuka, Y. Fujii, K. Maeda, Fatigue Fract. Eng. Mater. Struct., 27, 203 (2004) 
21. Y. Murakami, Metal fatigue : effects of small defects and nonmetallic inclusions (Elsevier, 2002) 